\title{
A escrita da mulher como consciência: o caderno, a contestação e a mudança proibidos
}

Joyce SCORALICK ${ }^{*}$

Waldyr IMBROISI ${ }^{* *}$

\begin{abstract}
Resumo: O presente trabalho tem como objetivo analisar o romance Caderno Proibido (Quaderno proibito), de Alba de Céspedes, estudando as relações entre a mulher da metade do século XX e aquilo que a cerca, e os contrastes entre os seus papeis e comportamentos esperados e o desenvolvimento de uma subjetividade, conscientemente apreendida a partir da escritura. A personagem principal, através da escritura de um diário secreto, denuncia os eventos que se dão a partir de suas relações com a família e a sociedade sexista da época, construindo um texto em que contrastam o discurso hegemônico, manifesto em seus atos e palavras, e um discurso anti-ideológico, calcado na construção de uma subjetividade com potência contrária ao esperado pelo meio.
\end{abstract}

Palavras-chave: Gênero. Caderno Proibido. Anulação. Escrita.

Abstract: This work aims at analyzing the novel Forbidden Book (Quaderno proibito), by Alba de Céspedes, studying the relationships joint among the women of the late $20^{\text {th }}$ century and what surrounds her and contrasting her expected roles and behavior with the development of a subjectivity, consciously apprehended from the scripture. The main character, by writing a secret diary, in which she denounces the events that take place from her relationship with her family and sexist society of the time, builds a contrasting text in a hegemonic discourse, manifest in his actions and words, and an anti-ideological one, based on the construction of a subjectivity with power by means contrary to the expected.

Keywords: Gender. Forbidden Book. Annulation. Writing.

\section{A mulher que se anula: a representação feminina em Caderno Proibido}

Alba de Céspedes, escritora ítalo-cubana, escreveu na Itália em um período do século XX marcado pelo fascismo. Através de sua literatura, conseguiu dar corpo a figuras femininas notáveis para seu tempo, dando a elas a dimensão psicológica que o regime não permitia aflorar. Vinda de família extremamente politizada, progressista e antifascista, Céspedes dedicou-se a causas como a iniciativa Pró-Cuba-Socialista, juntamente com o também ítalocubano, Ítalo Calvino.

A leitura de Caderno Proibido (1952) mostra que tais elementos da vida da autora nos ajudam a compreender o contexto em que suas obras foram produzidas e que embalaram a temática de sua escrita: a vida doméstica, por vezes amarga, da mulher dos anos trinta/ quarenta. Longe de se ter o objetivo de estabelecer uma leitura biografista do romance aqui

\footnotetext{
* Mestranda pelo PPG de Estudos Literários da Universidade Federal de Juiz de Fora. E-mail: scoralickj@ymail.com

*** Mestrando pelo PPG de Estudos Literários da Universidade Federal de Juiz de Fora. E-mail: waldyr.imbroisi@gmail.com
} 
analisado, pretende-se, com tal exposição, um entendimento um pouco maior daquilo que a autora experimentou ${ }^{1}$, já que, como nos lembra Natalia Ginzburg, "um escritor exprime, ainda que a contragosto, a sua própria bagagem de experiências [...] a literatura certamente reflete a vivência do autor e os fatos que acontecem naquele momento". Assim, a construção das personagens femininas de Alba de Céspedes nos denota o entendimento político e a preocupação com a posição subalterna, amarga, subjugada, resignada ou mesmo revoltada da mulher, importantes em tempos de regime fascista.

Em larga medida, as personagens femininas são construídas de uma maneira que reforce os estereótipos e as características frequentemente consideradas como pertencentes ao gênero feminino. Em diversas obras, escritas por homens e mulheres, é possível deslindar o "mecanismo narcísico do engendramento da personagem feminina" (BRANDÃO, 2006, p. 16), o que significa dizer que a personagem é dada como aquela que anula a si mesma em função de refletir e engrandecer a imagem do homem.

A obra de Céspedes demonstra claramente a tendência de Valéria, personagem principal, a renunciar a seus desejos em prol dos que lhe cercam. Desde renúncias simples, como deixar de escrever no caderno para lavar a louça da cozinha (CÉSPEDES, 1962, p. 4) ou ouvir músicas que lhe desagradam, a fim de agradar ao marido (CÉSPEDES, 1962, p. 28), até renúncias mais graves, como deixar de lado planos, propostas e possibilidades de afirmação - corporificadas pela viagem à Veneza e pela vivência de um romance secreto com Guido (CÉSPEDES, 1962, p. 218-20) -, Valéria apaga-se a fim de permitir que sua família tenha acesso ao que deseja.

A crença que ela interiorizou de que a mulher deve ocupar um papel submisso ao homem e ao lar aparece de forma indireta, na composição dos hábitos, pensamentos e ações da personagem e, por vezes, surge de forma explícita; em determinado momento, ela escreve no caderno: "sempre pertenci a ele [Miguel], aos meninos. Agora, contudo, parece-me às vezes estar ligada a todos sem pertencer a ninguém. Tenho a impressão de que uma mulher deve sempre pertencer a alguém para ser feliz" (CÉSPEDES, 1962, p. 58-9). Ora, tal postura liga a mulher a uma posição que é eminentemente submissa e servil, sendo totalmente coerente com as concepções dominantes que fundam uma ideia discursiva de feminilidade

\footnotetext{
${ }^{1}$ É interessante adiantar neste ponto que tal fato está em consonância com a teoria de Suely Rolnik, abordada mais à frente no trabalho, que afirma que escrevemos a partir daquilo que nos atinge, das marcas causadas pelos afetos que nos perpassam. A teoria pode ser aplicada, então, em dois níveis na obra (já que temos uma personagem escritora): da autora para o livro e da personagem para seu caderno. No presente trabalho, nos deteremos na segunda dessas relações.
} 
que toma o lugar de "real" para a personagem e para todos a seu redor (BUTLER, 2012, p. $58)$.

De fato, ela encara seu papel feminino, de cuidar do lar e submeter-se ao homem, como algo natural. Ao comparar as atitudes dela e de seu marido ao longo do casamento, ela diz: "Miguel dedicou toda sua vida a mim, aos nossos filhos. Eu também fiz o mesmo, é verdade; mas me parece mais natural" (CÉSPEDES, 1962, p. 80, grifo nosso). Ao dar o caráter de naturalidade ao comportamento feminino, Valéria está recorrendo a uma composição social da ideia de gênero que é historicamente construída, mas, em sua visão (e, podemos dizer, na de seus familiares), é considerada uma verdade fundante, pré-discursiva e pré-histórica, o que garante a continuidade e a não contestação dessa visão (BUTLER, 2012, p. 25). Valéria obedece à "compulsão cultural" de tornar-se mulher, sem perceber os meandros culturais e discursivos por trás de seu comportamento (BUTLER, 2012, p. 26).

A personagem, assim, sacrifica "tudo de si mesma" a fim de levar a cabo as tarefas domésticas que lhe são atribuídas como função, temendo e prevendo que se sua atuação não existisse, os outros membros da casa não "teriam sofrido" (CÉSPEDES, 1962, p. 115), posto que as tarefas que ela desempenha lhe são consideradas "óbvias, naturais" (CÉSPEDES, 1962, p. 25). Valéria ocupa um espaço "caracterizado pela imobilidade e fixidez, pois o alvo do olhar de Narciso [o homem] recai num espaço restrito, onde a sombra amada não pode estremecer, para não se deformar” (BRANDÃO, 2006, p. 113).

A anulação que Valéria processa passa, também, por uma composição dos significados e papeis que ela assume enquanto mulher. Ocupando, para os filhos, o papel da mãe, como seria esperado, para Miguel ela passa paulatinamente a representar apenas esse mesmo papel fixo, que se expressa explicitamente no modo com ele a chama. Em um episódio específico, fica clara a inquietação de Valéria com a desapropriação de seu papel de "mulher" e "esposa" pela fixidez da maternidade:

Comecei a chorar e ele me consolava. "Não faça isso, mamãe". Ouvindo-me chamar assim tinha, ao contrário, mais vontade de chorar; pois para ele, já desde alguns anos, represento apenas essa figura que agora está naufragando e me arrasta junto (CÉSPEDES, 1962, p. 66, grifo nosso).

Se as esperanças e ocupações da mãe estão restritas a esse papel, qualquer abalo gera desconforto e mesmo tristeza e desespero; esses abalos ocorrem,de maneira recorrente ao longo da obra, na difícil relação de Valéria com a filha Mirela, na impossibilidade da personagem de lidar com certas tarefas e na tendência a afastar-se do ambiente doméstico em 
direção ao trabalho. Pode-se dizer, ainda, que o escritório oferece a Valéria um espaço de afirmação, de vivência de uma identidade não marcada pelos imperativos discursivos da composição rígida de gênero, um espaço no qual, independentemente de ser mulher, ocupa uma função vital e é necessária pela qualidade do trabalho que realiza. Posteriormente, o escritório será ainda um espaço em que ela poderá viver com Guido uma espécie de amor há muito tempo deixado de lado em sua relação com Miguel.

Se essa posição engessada em que a narradora se encerra não é contestada pela mesma ao longo de sua vivência em família, o evento desencadeador da escrita do livro - a compra do caderno - possibilitará a ela, a partir de uma escrita que funciona como clínica e tratamento, reconhecer os meandros discursivos tomados como reais e repensar seus papeis e ações de forma mais livre.

\section{A escrita como tratamento e resposta}

Valéria, como percebido no trecho do primeiro dia de escrita do caderno, não pretendia adquirir tal objeto. Na sua costumeira - como parece - saída de domingo para comprar os cigarros enquanto seu marido ainda dormia (para que os encontrasse ao acordar), ela acaba por encontrar o caderno de capa preta e por desejá-lo, "precisar" dele, como ela mesma diz ao dono do estabelecimento. Ora, Valéria, como já vimos, anula-se frente aos desejos e necessidades da família e às opiniões dos homens (seu marido, pai e até mesmo Ricardo, em um grau diferenciado). Dessa maneira, não lhe parecia legítimo ter um caderno só seu, particular, já que tal opinião não era legitimada pela família. Assim, Valéria compra o caderno, proibido desde o momento da venda- e tal adjetivo adquire outras nuances, leva-o e o mantém escondido até o seu fim.

A escrita em tal diário se dá, a priori, de maneira que sua autora não identifica o exato porquê de ter adquirido o caderno e de escrever nele suas impressões, seus registros pessoais e secretos. No início, ela expressa na escrita tal indefinição sobre o papel do caderno e sobre a necessidade e impossibilidade de escondê-lo da família:

Não sei nem mesmo o que me levou a comprá-lo; foi um acaso. Jamais pensei em escrever um diário, mesmo porque um diário deve ser secreto e, por isso, deveria escondê-lo de Miguel e dos meninos. Não gosto de esconder coisas; além disso, em casa há tão pouco lugar que seria quase impossível consegui-lo. (CÉSPEDES, 1962, p. 1) 
Assim, Valéria iniciará um caminho para dentro de suas reflexões a partir da escrita: com a possibilidade de discursar e manter tal discurso apenas para si, ela enxerga - e realiza no caderno - a possibilidade de verdadeiramente colocar suas opiniões e desejos em pauta. A escrita do caderno é uma resposta àquilo que ela vive e um espaço no qual ela se permite realizar aquilo que não realiza no plano comportamental. Depreende-se, então, que Valéria se trata das "marcas", no termo de Suely Rolnik, que a atingem a partir da sua escrita. De acordo com a psicanalista:

Ora, o que estou chamando de marca são exatamente estes estados inéditos que se produzem em nosso corpo, a partir das composições que vamos vivendo. Cada um destes estados constitui uma diferença que instaura uma abertura para a criação de um novo corpo, o que significa que as marcas são sempre gênese de um devir. (ROLNIK, 1993, p. 242, grifo nosso)

A partir da tessitura que configura a vida - tecido no sentido dos entrecruzamentos de relações e sensações - as marcas acontecem, como cicatrizes de feridas que nos são causadas pelo ato mesmo de viver e ser perpassado por outras pessoas, por instituições, por proibições, enfim, por tudo o que nos afeta.

No invisível o que há é uma textura (ontológica) que vai se fazendo dos fluxos que constituem nossa composição atual, conectando-se com outros fluxos, somando-se e esboçando outras composições. Tais composições, a partir de um certo limiar, geram em nós estados inéditos, inteiramente estranhos em relação àquilo de que é feita a consistência subjetiva de nossa atual figura. Rompe-se assim o equilíbrio dessa nossa atual figura, tremem seus contornos. Podemos dizer que a cada vez que isso acontece, é uma violência vivida por nosso corpo em sua forma atual, pois nos desestabiliza e nos coloca a exigência de criarmos um novo corpo - em nossa existência, em nosso modo de sentir, de pensar, de agir etc. - que venha encarnar esse estado inédito que se fez em nós. E a cada vez que respondemos à exigência imposta por um desses estados, nos tornamos outros. (ROLNIK, 1993, p. 242).

Cada marca é, então, um estado inédito (sempre novo, por excelência) que exigirá ganhar novo corpo, já que um estado inédito não pode ser encarnado (ou abarcado) pelo "velho corpo", que ainda não está familiarizado com a diferença que se instaurou ${ }^{2}$. Desta feita, é necessário escrever para criar os corpos novos que conterão esses estados novos e,

\footnotetext{
${ }^{2}$ Faz-se necessário lembrar que Rolnik utiliza-se do conceito de devir no sentido deleuzeano, ou seja, um movimento de mão-dupla que configura um momento de indiferenciação entre os dois elementos que entram em devir. Em tal processo, tais elementos se modificam mutuamente em mesmo grau e o devir é, por definição, sempre inédito.
} 
assim, se pode lidar melhor com tais estados: tratar as cicatrizes e estar pronto para receber as novas e inevitáveis, ainda que sejam apenas reverberações das antigas:

Cada marca tem a potencialidade de voltar a reverberar quando atrai e é atraída por ambientes onde encontra ressonância. [...] Quando isto acontece, a marca se reatualiza no contexto de uma nova conexão, produzindo-se então uma nova diferença. E mais uma vez somos tomados por uma espécie de "desassossego", [...] E mais uma vez nos vemos convocados a criar um corpo para a existencialização desta diferença. (ROLNIK, 1993, p. 242)

Sob tal luz, é possível ler a continuidade e o caráter inexorável da escrita de Valéria, que ela não deseja ou pensa ser possível interromper. "Fui deitar-me cedo, hoje à noite, mas não podia dormir. A escuridão me oprimia; palavras, imagens [...] Quando finalmente o encontrei [o caderno], apertei-o contra mim, como a um tesouro." (CÉSPEDES, 1962, p. 111). A partir do caderno, a autora do diário toma consciência das composições a sua volta, ela abre um espaço para ser a "Valéria" também em casa, já que lá era a "mamãe”, e coloca de maneira livre suas verdadeiras opiniões próprias e desejos verdadeiros, não cerceados pela opinião do marido, a qual segue no plano do comportamento, da "vida real". A atualização de suas opiniões e vivências no caderno funciona como possibilidade de compreender-se a si mesma, frente ao tratamento da escrita.

Seguindo tal linha de análise, a escrita do diário mostra-se medicinal para Valéria: escrever a trata de tais violências, a partir do momento em que é a escrita que configura o espaço no qual ela pode discursar à vontade sobre aquilo que a incomoda ou aflige, colocando, ou despejando, tais questões em um espaço neutro e particular. $\mathrm{Na}$ teoria de Deleuze, a escrita se configura como clínica, tratamento para tais afetos. Ainda que no pensamento do filósofo as considerações sejam feitas acerca de literatura e o caderno de Valéria não se pretenda literário, é possível à teoria abarcar tal circunstância, na medida em que o diário em questão configura o processo de escritura de que falava Deleuze, este mais lato que apenas a escrita artística.

Não que o escritor tenha forçosamente uma saúde de ferro [...] mas ele goza de uma frágil saúde irresistível, que provém do fato de ter visto e ouvido coisas demasiado grandes para ele, fortes demais, irrespiráveis, cuja passagem o esgota (DELEUZE, 1997, p. 14).

É também válido lembrar que a escrita como clínica não passa por um estado que se poderia chamar de "desânimo" inerte, frente àquilo que se experimenta como violência. Antes, é um processo de enfrentamento de tais cicatrizes, já que o ser que escreve não assume 
posição de passividade: ele vê na escrita exatamente a sua saída, o seu remédio necessário e potente. Deleuze nos lembra que não se trata de escritura, mas de processo de tratamento:

Por que se escreve? É que não se trata de escritura. É possível que o escritor tenha uma saúde frágil, uma constituição fraca [...] à medida que ele é somente fraco demais para a vida que o atravessa ou para os fatos que passam por ele. Escrever não tem outra função: ser um fluxo que se conjuga com outros fluxos - todos os devires-minoritários do mundo. (DELEUZE \& PARNET, 1998, p. 63).

Por tal razão, a escrita do diário pode ser analisada analogamente ao processo de cura/ tratamento pelo discurso que ocorre em certos processos medicinais, tais como a análise. No âmbito dessa clínica, Valéria administra o purgar de certos problemas, trabalha a rememoração e concatenação dos fatos, levando-se à reflexão e, com isso, forma para si um espaço em que se realizam os desejos e em que ela permite colocar aquilo que os seus outros loci não permitem ${ }^{3}$. Observemos o seguinte excerto, no qual Valéria demostra os dois vieses a que nos referimos:

São duas horas da madrugada, levantei-me para escrever: não conseguia dormir. Mais uma vez a culpa é deste caderno. Antes esquecia logo o que acontecia em casa; agora, ao contrário, desde que comecei a tomar nota dos acontecimentos diários, retenho-os na memória e tento entender porque eles se produziram (CÉSPEDES, 1962, p. 13, grifos nossos).

\section{Conflito de gerações e contradições}

Valéria tem quarenta e três anos na época em que escreve o diário. Tal idade, vista com olhos acostumados à ótica sexista da década de 50, é expressa na escrita da narradora como avançada, ainda que ela não pense dessa maneira - mas aja como se pensasse, muitas das vezes. Ela se encontra presa ao seu papel historicamente estabelecido/ imposto de "mamãe", pois ainda que trabalhe, isso é visto como complementação e até como capricho, que já deixou de ser esposa, de dona de casa e de esmerada "rainha do lar". No excerto abaixo, Valéria expressa a opinião negativa que sua família, ou seja, os homens e principalmente Ricardo, que expressa mais que Miguel suas opiniões sexistas, tem sobre o fato de as mulheres trabalharem:

\footnotetext{
${ }^{3}$ Tal fato é confirmado através da observação da relação existente entre opiniões e sensações expressas no caderno, que são opostas àquilo que se configura, de fato, nas ações de Valéria, como veremos adiante.
} 
Hoje, [Ricardo] declarou que as mulheres se aproveitam do trabalho para fazer o que lhes agrada. Lembrei-lhe que também eu trabalho e que foi uma vantagem para a nossa família, para eles também. Retrucou que o faço apenas por necessidade e que, portanto, meu trabalho é uma prova de solidariedade para com meu marido, uma prova de submissão, no fundo (CÉSPEDES, 1962, p. 100).

Nesse e em vários outros trechos, Valéria expressa a decepção que tal visão causa nela, já que considera seu trabalho importante e reconhece que é necessária e indispensável no escritório. Com isso, há uma tensão que se soma às outras, já que ela gosta de seu trabalho, reconhece que lá ela pode ser "Valéria" e não "mamãe" ou "bebê", como é chamada pela mãe, e percebe que à sua volta, em seu núcleo familiar, é vista como uma mulher já velha que tem seu trabalho apenas como símbolo da boa esposa prestativa que é.

O conflito de gerações que Valéria tem com os filhos se apresenta de modo bastante interessante: sua relação boa com Ricardo, homem que representa e serve aos ideais machistas, e seus frequentes atritos com Mirela, devido a suas atitudes e opiniões livres e "modernas", mostram que Valéria, ainda que tenha no caderno uma tomada de consciência de sua situação e um lugar em que manifesta a pulsão de sair de tal ciclo vicioso, está presa pelas próprias posturas dentro do esquema de vida que lhe foi imposto - e que ela aceita, ainda que com uma triste e inerte resignação ${ }^{4}$.

Expressamente diferentes, as relações entre Valéria e os filhos aparecem sempre em termos assim: "Jamais entendi Mirela, ao passo que sempre compreendo Ricardo" (CÉSPEDES, 1962, p. 128), compreendido a partir do que analisamos acima. Nas atitudes, a mãe sempre compra cigarros para Ricardo, pede a Mirela que o sirva e o toma sempre em mais alta consideração em relação à filha, ainda que ele só estude e que ela estude e trabalhe. No trecho a seguir, é notória a marca patriarcal no comportamento que Valéria impõe a Mirela, quando a manda que leve um prato para Ricardo, que estaria cansado e deveria ser servido:

Depois estendi-lhe um prato com os ovos fritos e pedi-lhe que o levasse para o irmão. Perguntou-me porque ele mesmo não podia vir buscá-lo. "Vou chamá-lo", disse. Voltei-me para ela duramente: "Obedeça", impus-lhe, "Ricardo está cansado, estudou o dia inteiro". "E você não trabalhou o dia inteiro?", objetou bruscamente: "E eu não trabalhei o dia inteiro?" Assim mesmo, foi levar o prato. Quando voltou disse: "Isto é o que me revolta

\footnotetext{
${ }^{4}$ É necessário ressaltar neste ponto que a resignação à qual nos referimos não se relaciona ao fato de Valéria escrever o caderno, fato que representa exatamente o contrário, mas sim ao final que o diário tem, ser queimado como símbolo da destruição do espaço do desejo, representando a triste aceitação da situação estabelecida fora dele.
} 
mamãe. Você se julga obrigada a servir todos, começando por mim. Então também os outros, pouco a pouco, acabam acreditando. Você acha que é um erro uma mulher ter algumas satisfações pessoais além daquelas da casa e da cozinha: que a sua única tarefa é a de servir. Eu não quero, compreende? não quero." Senti um arrepio na espinha, um arrepio gelado, do qual ainda não posso libertar-me. Todavia, demonstrei não dar importância àquilo que ela dissera. Perguntei-lhe, ironicamente, se é na sua casa que quer começar a ser advogado [sic] (CÉSPEDES, 1962, p. 98-99).

O interessante de tais conflitos é que Valéria, de fato, parece não perceber a oposição entre o que pensa e o que faz: de maneira bastante natural ela coloca o "arrepio gelado", a compreensão dos motivos de Cantoni (CÉSPEDES, 1962, p. 161) e as vontades expressas apenas no caderno, que são contra a natureza de suas relações, que coexistem e não causam nenhuma contradição em suas reflexões.

Tais dualidades no comportamento aparecem nos conflitos de gerações que a narradora tem com seus filhos e com sua mãe. Marcadamente diferentes por causa da imposição de papeis bem específicos e rígidos, ou da contestação desses papeis, a mãe de Valéria e Mirela representam pontos referenciais, na medida em que a mãe representa a rigidez do hábito e do matriarcado submisso, relações das quais ela quer fugir, e Mirela alguém que não deseja ser como a própria mãe é, e por isso trabalha e estuda com perspectivas de futuro profissional, e não deseja ser servil e caseira. Valéria expressa ter consciência, ainda que rasa, de tais questões: "É preciso, talvez, ficar quase velha e ter filhos grandes, como eu tenho, para compreender os próprios pais e, refletindo-se neles, entender um pouco mais de nós mesmos" (CÉSPEDES, 1962, p. 39).

A partir da visão do parâmetro colocado por aquilo que a mãe é, dos seus comportamentos sempre iguais, de sua postura dura e de seu incessante trabalho doméstico, Valéria se vê vencedora e evoluída. Mas, ao confrontar-se com Mirela, as diferenças entre a dona do diário e sua mãe não parecem mais tão distantes, e Valéria percebe-se em um ponto intermediário desconfortável. Mirela demonstra acreditar que a mãe tem medo de se confessar desconfortável com a própria condição dual, como comprovado no discurso de Cantoni: "Talvez Mirela tenha razão quando diz que a senhora entende e tem medo de confessá-lo" (CÉSPEDES, 1962, p. 161)

Já na relação com Ricardo, Valéria sente conforto. Sendo o filho representante dos ideais sexistas partilhados pela maioria dos homens da época, a mãe consegue compreendê-lo e prever seus comportamentos, tratando-o um pouco como trata o próprio marido, enfim, são homens, como se percebe no trecho acerca do jantar que Mirela foi obrigada a servir ao 
irmão, nas páginas 98 e 99 do romance, citado acima. Valéria sempre partilhou e professou as opiniões dos homens que tinham as rédeas de sua vida (pai, marido), sendo para ela bastante compreensíveis as atitudes do filho e, ao analisar os comportamentos de todos, afirma: "Às vezes, penso que só Ricardo e eu somos pessoas normais.” (CÉSPEDES, 1062, p. 149).

Dessa maneira, constroi-se uma relação em que Valéria representa para Ricardo o ideal de mulher que ele buscará em sua esposa; ele procura uma mulher que, como a mãe, aceite anular-se pela figura narcísica do homem: "[Marina] Dedica-se inteiramente a mim, posso mandá-la fazer o que quero, tem um caráter doce, condescendente" (CÉSPEDES, 1962, p. 79). O interessante em tal aspecto da relação é que Valéria, mesmo deixando entrever no caderno que deseja ser mais como Mirela, não consegue perceber tais nuances de incoerência, e afirma que ninguém será para Ricardo o que ela conseguiu ser como mãe de família - e que, ainda que não expresso objetivamente, ou conscientemente, ela mesma é substituta da sogra como a nova "mamãe" de Miguel - e de toda a família (CÉSPEDES, 1962, p. 101).

O espaço ocupado pela personagem principal entre a geração anterior - a da mãe, cujas atitude e comportamentos são essencialmente sexistas e firmes, chegando a evidentes exagerações as quais a filha não compartilha - e da geração imediatamente seguinte - a de Mirela, marcada pelo pós-guerra, pela liberdade feminina que se anuncia - coloca-a em uma situação conflituosa, tanto em termos de compreensão da realidade quanto em termos de formação de uma subjetividade coerente. A contestação de tudo aquilo que antes era respeitado, ou daquilo que se deveria fingir que se respeitava, (CÉSPEDES, 1962, p. 199) introduz-se no pensamento de Valéria, ao mesmo tempo em que as construções sociais, corporificadas pela mãe, permanecem fortes para ela. Desenvolveremos a forma como esse conflito se expressa a partir do caderno na seção seguinte.

\section{Os discursos se desestabilizando}

Varium et mutabile semper femina

Vimos até então como o comportamento de Valéria, no romance em questão, funciona de acordo com a ideologia machista dominante; vimos ainda como o comportamento de seus familiares reforça essa ideologia dominante, no caso de Ricardo, mais explicitamente, e de Miguel, a partir dos hábitos e comportamentos interiorizados, ou oferece contestação, no caso 
de Mirela, que despreza a moral ditada pelos pais e confronta-se diretamente com a mãe. Observamos, ainda, que o caderno é um espaço no qual a personagem tem condições de representar, reconhecer e desenvolver sua subjetividade, conhecendo pensamentos íntimos aos quais não tinha acesso direto antes da experiência da escritura.

$\mathrm{Na}$ nossa leitura, é possível distinguir dois discursos que se interpenetram ao longo da narrativa: o primeiro deles é a narrativa do que acontece no cotidiano da família e do trabalho de Valéria; o segundo é o das reflexões e dos apontamentos que a mesma faz sobre sua vida. Ao passo que o primeiro, baseado na experiência empírica, é um relato dos acontecimentos e esforça-se por ser um retrato da realidade, o segundo é composto por comentários, pensamentos e anseios que, tendo por base o vivido, refletem sobre ele, modificam-no e se deixam modificar por ele.

É possível dizer que a narrativa dos fatos segue uma postura que se harmoniza com a ideologia e a lógica habitual com que a sociedade acostumou-se a enxergar a feminilidade; Valéria adéqua-se ao que se espera dela enquanto mulher e mãe. No entanto, as inquietações da personagem são essencialmente contraideológicas, posto não repousarem sobre a continuidade e o nível do contínuo e do real (SANT’ANNA, 2012, p.37), demonstrando um pensamento que se constrói de maneira totalmente diversa dos seus hábitos e práticas diárias.

Os dois níveis discursivos, longe de se excluírem, se modificam; a tendência inicial do romance é que o discurso da reflexão, desenvolvido no caderno, passe aos poucos a penetrar na realidade cotidiana e modificar-lhe os atos. Ao provocar o refletir sobre sua condição, a escrita leva Valéria a se permitir ter um caso com Guido, um homem casado, a ouvir, até o fim, as palavras de Cantoni, dedicando-lhe quase sem querer, certa simpatia, e a descuidar, com certa freqüência, das tarefas domésticas: o caderno é, então, a partir da reflexão que propõe e configura, a desestabilização daquilo que antes parecia/ era fixo na vida dela.

Eu nunca tive ideias pessoais; apoiei-me até agora a uma moral aprendida quando criança ou àquilo que dizia meu marido. Parece-me, agora, que não sei mais onde está o bem e onde está o mal, não consigo mais entender as pessoas que me rodeiam e, por isso, também aquilo que julgava sólido em mim perde consistência. (CÉSPEDES, 1962, p. 130)

A nova reflexão e o novo pensamento são, assim, desencadeadores de novas atitudes, de um comportamento e da produção de um estranhamento do que antes seria tomado como verdade (SANT'ANNA, 2012, p. 33), desestabilizando o supostamente firme corpo cultural construído. A personagem passa, aos poucos, de mãe e dona de casa a empregada do 
escritório, e a amante, denotando uma complexidade e modificação apenas possíveis a partir do ato da escritura. Se as mulheres "se acostumem mais depressa às situações novas, pensem menos, em geral, e por isso as aceitem sem justificá-las” (CÉSPEDES, 1962, p. 56), Valéria torna-se paulatinamente um exemplo de não-mulher, dentro do discurso sexista que assume o espaço do "real" (BUTLER, 2012, p. 58). :

De forma ambígua, à medida que a relação com Guido vai tornando-se mais séria e intensa, ela alterna-se entre um remorso absoluto e a falta completa de arrependimento: "de uns tempos pra cá, parece-me que em mim tudo é pecado" (CÉSPEDES, 1962, p. 137), e "Pensei em Miguel, nos meninos, mas não experimentava remorso algum, estava calmíssima" (CÉSPEDES, 1962, p. 142). A consciência que se adquire na escrita vai aos poucos invadindo a vivência, sem jamais chegar ao ponto de contestá-la diretamente.

No último capítulo, no entanto, uma modificação se processa no sentido inverso. $\mathrm{O}$ futuro nascimento de um neto, a necessidade de cuidar da criança e a mitigação dos planos de Valéria de viajar para encontrar-se escondido com Guido e, enfim, consumar completamente a traição, são fatores que levam a personagem a se reposicionar dentro da lógica dominante. Se o discurso anti-ideológico do caderno invadia, aos poucos, a vida da personagem, em um momento final ela forçará o discurso dominante a ocupar e tolher o espaço privilegiado que é o caderno. No último capítulo do livro, de forma genial, mesmo o tom da escrita de Valéria se modifica: ela narra a renúncia ao amor de Guido e a necessidade de cuidar da criança que irá nascer, filha de Marina e Ricardo.

O sofrimento, o desespero e a desorganização do texto nos capítulos anteriores, em que a escrita é usada como clínica, dá lugar a uma escrita organizada e decidida, marcada por expressões de falsa paz, como "sensação de refrigério" (CÉSPEDES, 1962, p. 218) e "parecemos claros e leais" (CÉSPEDES, 1962, p. 222), e por justificações antes jamais levantadas da sua renúncia, como no trecho "E quando o vejo tirar várias notas de grande valor, procurando cem liras para pagar o café, não gosto" (CÉSPEDES, 1962, p. 220), lembremo-nos do gosto de Valéria pela riqueza de Guido, e no trecho "Ninguém pode tomar conta de uma criança melhor do que a avó" (CÉSPEDES, 1962, p. 220), e em momento algum ela parece ter confiado a educação de Ricardo e Mirela a sua mãe, esta mudança marca, no plano da narrativa ideológica, da construção do personagem e mesmo da linguagem, um retorno à ideologia, uma submissão a ela.

Ainda, marcado por uma consciência cruel da sua fraqueza e da sua escolha, desponta uma certeza de que não tomava o caminho correto, mas ainda assim tomava-o sem hesitar: 
“minha renúncia é apenas outra prova daquela falta de coragem que Mirela chama de hipocrisia" (CESPEDES, 1962, p. 221). O caderno, fator perturbador e que desengata a consciência, é dominado, também, nesse último dia, pela repressão.

Se a personagem feminina tem por opções na literatura de engendramento narcísico "ou refletir a imagem masculina, metonímia e metáfora de uma ideologia opressora, ou perder-se no vazio da loucura e da marginalização" (BRANDÃO, 2006, p. 125), Valéria acaba escolhendo a primeira opção a partir da negação (FREUD, 2006, p. 265) dos seus desejos e inclinações. O discurso ideológico cotidiano se apossa do espaço por excelência do discurso contraideológico, e a personagem decide pela obscuridade e infelicidade de permanecer imobilizada. Tal "opção" marca a dificuldade cruel da mulher de se libertar das amarras de sua posição socialmente instituída, e na obra como um todo, se chega, no nível do enunciado, a uma conclusão que se adéqua aos princípios vigentes, no nível da enunciação constitui uma crítica grave ao modelo sexista, à subjugação feminina e a tudo ao que Valéria se vê submetida, sem ter forças suficientes para vencer.

\section{Referências}

ALMEIDA, M. O esvaziamento dos papéis engendrados como estratégia de crítica social. In NASCIMENTO, E; OLIVEIRA, M. C. C. e ZIMBRÃO, T. V. (Org.). Literatura em Perspectiva. Juiz de Fora: Editora da UFJF, 2003, p. 77-91.

BRANDÃO, R. S. Mulher ao pé da letra: a personagem feminina na literatura. Belo Horizonte: Editora UFMG, 2006.

BUTLER, J. Problemas de gênero: feminismo e subversão da identidade. Trad. Renato Aguiar. Rio de Janeiro: Civilização Brasileira, 2012.

CÉSPEDES, A. Caderno Proibido. Trad. Carla Inama de Queiroz. Rio de Janeiro: Editora Civilização Brasileira, 1962.

DELEUZE, G; PARNET, C. Diálogos. Tradução: Eloísa Araújo Ribeiro. São Paulo: Escuta, 1998.

DELEUZE, G. Crítica e Clínica. Trad. Peter Pál Pelbart. São Paulo: Ed 34, 1997.

FREUD, S. O Ego e o id. Rio de Janeiro: Imago, 2006.

ROLNIK, S. Pensamento corpo e devir - uma perspectiva ético/ estético/ política no trabalho acadêmico. In: Cadernos de subjetividade. São Paulo: PUC 1993, nº 2.

SANT'ANNA, A. R. Análise estrutural de romances brasileiros. São Paulo: Editora UNESP, 2012. 